as celestial bodies were moving as storm-centres drift, eastward.

Would it not be of interest to learn from correspondents how far the gay deceiver was seen? It was so exceptionally striking, that no'person favorably situated could have failed to observe it, and no one could but be impressed by the beauty of the unusual event.

L. W. LEDYARD.

Cazenovia, N.Y., Feb. 18.

\section{The Fiske Range-Finder}

WITH reference to the note of Lieut. Casey in your issue of Jan. 31, 1890, calling attention to an apparent hiatus in the theory of my range-finder, permit me to say that Lieut. Casey is entirely correct in all his statements and deductions, but that the instrument does in reality make an automatic correction which has not yet been publicly described. There are a number of ways of accomplishing it; but it does not seem advisable to describe any of them yet, in view of patent applications now pending.

Norfolk, Va., Feb. 12.

BRADLEY A. Fiske, U.S.N.

\section{Answers}

49. INFLUENZA. - In reply to the query in Science of Jan. 17, "Has epidemic influenza been known to cross the equatorial line?" I beg to append the following: The epidemic of 1836-37, which originated probably in Russia, "also spread to the southern hemisphere, and prevailed at Sydney and the Cape of Good Hope at the same time that it visited the north of Europe" (Cyclopodia of Medicine, Von Zremssen, ii. p. 522).

HARVEY B. BASHORE.

West Fairview, Penn., Feb. 17

\section{INDUSTRIAL NOTES.}

\section{Improvements in Electric Motors.}

IN Science of Dec. 13, the Crocker-Wheeler electric motor, as applied to pumps and fans, was illustrated and described. The accompanying engravings show the improved motor as now manufaciured by the Crocker-Wheeler Company, and also an improved starting-switch and device for adjusting the speed and power.

The improved motors contain all the features which, during several years' experience in the manufacture and operation of a large number of successful motors, have been found to increase their strength, economical use of current, general appearance, and their convenience for starting, stopping, and regulating. The construction has been improved to permit the use of wire on the armature two sizes larger than has been possible before, therefore making the winding much less liable to breakage, and enabling it to carry more current without heating. The borse-power motor is made to run at a practically steady speed, even with the most sudden and beavy changes of load. The base is made extra heavy, with the centre of gravity low, to add to the steadiness and solidity of the machine. The bearings are made of the best babbitt metal, the same as on large steam-engines and other first-class machinery, this being a new feature in small motors.

The efficiency of these machines, or the amount of power that they will furnish from the consumption of a given amount of electricity, has been materially increased. The direction of rotation is made reversible by simply changing the brushholders, and considerable advance is made in the finish of the machine, the best workmanship being bestowed upon every part.

With the adjusting-switch in the position shown in Fig. 2, these vnotors run at full speed $(1,900$ revolutions per minute), and in the position shown in Fig. 3 they run at about half speed. The windings are so proportioned that in either case the proper current flows through, and runs the motors at the respective speeds with high efficiency.
The new ' $K$ ', winding on these machines takes the place of the lamp frequently used on the top of other motors to vary the speed. It is a radical improvement in this respect, saving the current usually wasted on the lamp, and giving a means of instantly changing the motor's speed by turning the knob

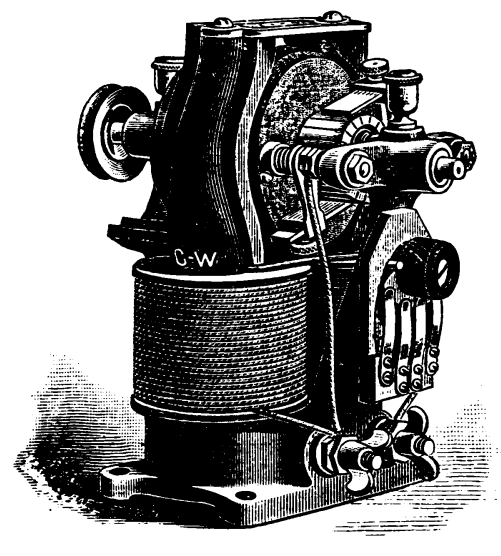

FIG. 1

without the use of resistance-boxes or the trouble of unscrewing and removing a lamp. The starting-switch is shown in Fig. 4.

The arrangement is adapted to running fans, pumps, and all kinds of machinery that are not subject to extreme variations, and is superior for these purposes on account of the facilities it

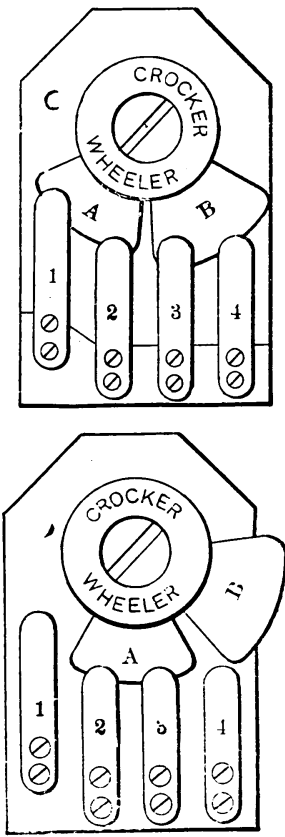

FIGS. 2 AND 3.

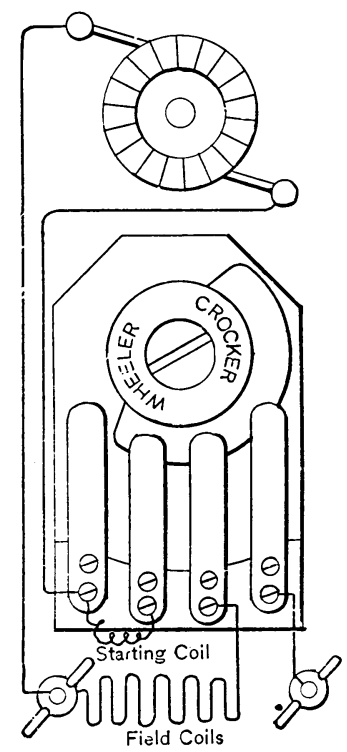

FIG. 4 . offers of changing the speed. For work which is variable and sometimes thrown off entirely, as in the case of buff-wheels, lathes, etc., the constant speed motors are preferable, because they maintain steady speed at all times.

\section{The Springfield Industrial Drawing-Kit and Drawing-Model Support.}

Every draughtsman finds a drawing-board, a T-square, and one or more triangles as essential to his work as are the scale of inches and the compasses, and every pupil in mechanical drawing requires a similar outfit. The Springfield industrial drawing kit, shown in the illustrations, is intended for use in grammar and high schools, the family, the office, and the shop.

The set (Fig. 1) consists of a board about ten by twelve inches, 